ous diagnosis of parkinsonism is of some concern and deserves further attention.

We thank all the general practitioners who allowed us to study their patients and who contacted them for the purpose of this study; Professors Ley Sander and Simon Shorvon, who allowed us to cooperate with some of the practices participating in the linkage scheme between the National Hospital for Neurology and Neurosurgery in London and several surrounding general practices; and all the patients.

Contributors: All authors designed the study. AS assessed the patients and discussed their diagnoses and videotapes with NPQ, who was also involved in the assessment. AS and YB-S did the analyses. All authors helped to write the paper. NPQ will act as guarantor for the paper.
Funding: The study was supported by a grant from SmithKline Beecham.

Competing interests: None declared.

1 Brewis M, Poskanzer DC, Rolland C, Miller H. Neurological disease in an English city. Acta Neurol Scand 1966;42:1-89.

2 Sutcliffe RLG, Prior R, Mawby B, McQuillan WJ. Parkinson's disease in the district of the Northampton Health Authority, United Kingdom. A study of prevalence and disability. Acta Neurol Scand 1985;72:363-79.

3 Mutch WJ, Dingwall-Fordyce I, Downie AW, Paterson JG, Roy SK. Parkinson's disease in a Scottish city. BMJ 1986;292:534-6.

4 Sutcliffe RLG, Meara JR. Parkinson's disease epidemiology in the Northampton district, England, 1992. Acta Neurol Scand 1995;92:443-50.

5 Schrag A, Ben-Shlomo Y, Quinn NP. The population prevalence of progressive supranuclear palsy and multiple system atrophy. Lancet 1999:354:1771-5.

(Accepted 5 April 2000)

\title{
Ten year audit of secondary prevention in coronary bypass patients
}

\author{
R John Irving, S Helen Oram, John Boyd, Philip Rutledge, Fergus McRae, Peter Bloomfield
}

Department of Medical Sciences, Western General Hospital, Edinburgh EH4 2XU

R John Irving British Heart

Foundation junior research fellow

Department of Cardiology, Royal Infirmary of Edinburgh,

Edinburgh EH3 9YW

S Helen Oram

medical studen

Peter Bloomfield consultant cardiologist

Department of Clinical Audit, Roval Infirmary of Edinburgh

John Boyd audit officer

Lothian Health, The Pleasance, Edinburgh BH8 9RS

Philip Rutledge medical prescribing advisor

Broxburn Medical Centre, Broxburn, West Lothian EH52 5JZ

Fergus McRae general practitioner

Correspondence to: P Bloomfield PSBloomfield@ compuserve.com
Treatment of risk factors in patients who have had coronary artery bypass surgery improves their prognosis. ${ }^{12}$ A national survey performed in Britain in 1994 showed that risk factor management was suboptimal in most patients who had had bypass surgery. ${ }^{3}$ This survey was carried out before the publication of landmark trials showing the benefit of reducing cholesterol concentration. ${ }^{45}$ To determine if secondary prevention has changed as the evidence has improved, we audited the management of patients who had had bypass surgery in Lothian over the past decade.

\section{Subjects, methods, and results}

We identified a random sample of 100 patients a year from 1988 to 1997 from the database of cardiothoracic surgery in our regional centre. We sent postal questionnaires to their general practitioners about current aspirin treatment, smoking status, blood pressure, and cholesterol concentration and treatment and compared responses with local audit standards. We received completed questionnaires from 94 practices about $761(76 \%)$ patients, of whom 563 were alive. Aspirin was prescribed to $451(80 \%)$ patients, and 65 $(12 \%)$ continued to smoke. Seventy patients $(12 \%)$ had systolic pressure greater than $160 \mathrm{~mm} \mathrm{Hg}$ and $43(8 \%)$ had diastolic pressure greater than $90 \mathrm{~mm} \mathrm{Hg}$. These risk factors did not vary by year of operation.

The proportion of patients with cholesterol measured and below the audit standard $(<5.2$ $\mathrm{mmol} / \mathrm{l})$ rose from $12 \%(5 / 42)$ for those operated on in 1988 to $50 \%$ (37/72) for those operated on in 1997. The proportion of patients with correctly managed cholesterol significantly increased for those operated on after publication of the Scandinavian simvastatin survival study in 1994 (figure, $\mathrm{P}<0.0001$ ). ${ }^{4}$ Two hundred and seventy patients $(48 \%)$ attended practices that had audited their management of secondary prevention, but the proportion of patients managed appropriately was virtually identical in audited and non-audited practices (37\% (99/270) v 34\% (99/291), $\mathrm{P}=0.956)$.

\section{Comment}

Our audit has shown that the standard of secondary preventative care was good for well established risk factors $^{3}$ but less good for management of cholesterol. Although there has been considerable improvement over the past decade, $48 \%$ of patients were still not managed optimally in 1997. Patients who had bypass surgery before the 1994 study $^{4}$ were less likely to receive cholesterol lowering treatment, probably because they had been discharged from specialist review and were less likely to consult their general practitioner.

The proportion of patients with suboptimally managed cholesterol was similar in practices that had and

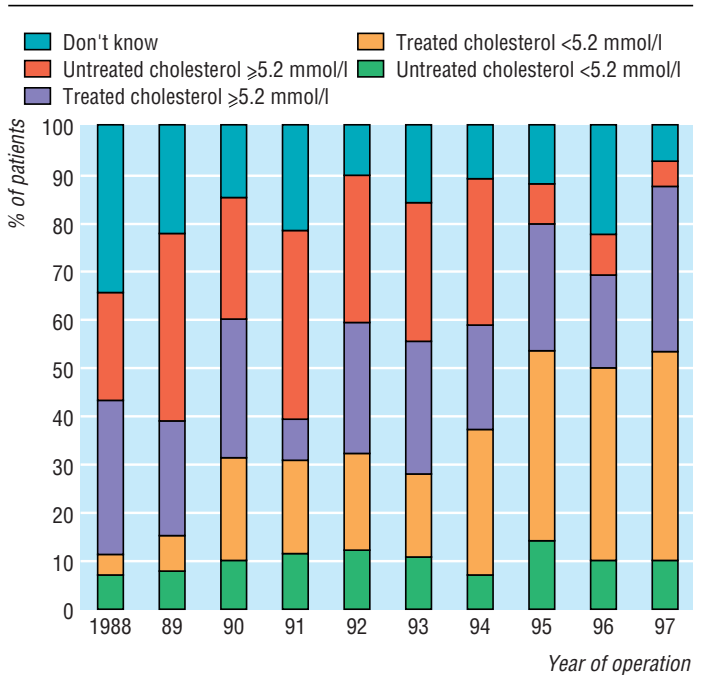

Measurement and treatment of raised cholesterol concentration among patients by year of coronary artery bypass surgery 
had not audited their secondary prevention. Many of the audited practices had participated in an audit organised by the local primary care audit team shortly before our survey, and improvement in care may have not yet been evident. However, audits usually identify patients by a diagnosis of myocardial infarction or the prescription of drugs for angina and may not identify coronary bypass patients. Use of hospital databases could improve identification of patients who would benefit from treatment. Our survey did not include data on patient compliance, which may also be an important factor.

In 1999, Lothian Health initiated a further project using a computer based audit package to identify patients and ensure that they are assessed within general practice. This project is funded to enable the practice teams to devote sufficient time to the process. To date 74 practices out of 125 within Lothian have enrolled to participate. Our results suggest that this project has the potential to improve secondary prevention in many patients with coronary heart disease, but it will need to be assessed by future audit.

Contributors: RJI supervised posting and analysis of questionnaires, analysed the results, and wrote the paper. $\mathrm{SHO}$ arranged posting and analysis of questionnaires, performed an early analysis of results, and helped write the paper. JB organised the database and helped write the paper. PR and FM designed the questionnaire and helped write the paper. PB arranged funding, supervised the project, designed the questionnaire, and wrote the paper. He is the guarantor.

Funding: The project was supported by grants from Pfizer and Parke-Davis and the Royal Infirmary audit department

Competing interests: Merck Sharp and Dohme sponsored a visit by $\mathrm{PB}$ to the American College of Cardiology annual meeting. He has also carried out sponsored research for Merck Sharp and Dohme, Pfizer, and Bristol-Myers Squibb, all of whom make statins. RJI has also received sponsorship to attend a meeting in the United States from Merck Sharpe and Dohme.

1 Campeau L, Knatterud G, Domanski M, Hunninghake D, White C, Geller $\mathrm{N}$, et al. The effect of aggressive lowering of low-density lipoprotein cholesterol levels and low-dose anticoagulation on obstructive changes in saphenous-vein coronary-artery bypass grafts. N Engl J Med 1997;336: $153-62$.

2 Cavender JB, Rogers WJ, Fisher LD, Gersh BJ, Coggin CJ, Myers WO. Effects of smoking on survival and morbidity in patients randomized to medical or surgical therapy in the coronary artery surgery study (CASS): 10-year follow-up. J Am Coll Cardiol 1992;20:287-94.

3 Bowker TJ, Clayton TC, Ingham J, McLennan NR, Hobson HL, Pyke SDM, et al. A British Cardiac Society survey of the potential for the secondary prevention of coronary disease: ASPIRE (action on secondary prevention through intervention to reduce events) principal results. Heart $1996 ; 75: 334-42$.

4 Scandinavian Simvastatin Survival Study Group. Randomised tria of cholesterol lowering in 4444 patients with coronary heart disease: the Scandinavian simvastatin survival study (4S). Lancet 1994;344: $1383-9$.

5 Sacks FM, Pfeffer MA, Moye LA, Rouleau JL, Rutherford JD, Cole TG, et al. The effect of pravastatin on coronary events after myocardial infarction in patients with average cholesterol levels. $N$ Engl $J$ Med $1996 ; 335: 1001-9$

(Accepted 24 February 2000)

\section{Correction}

Iron supplemented formula milk related to reduction in psychomotor decline in infants from inner city areas: randomised study

Several errors occurred in this paper by Williams and others (13 March 1999, pp 693-8). Because earlier versions of the figures were inadvertently submitted with the final

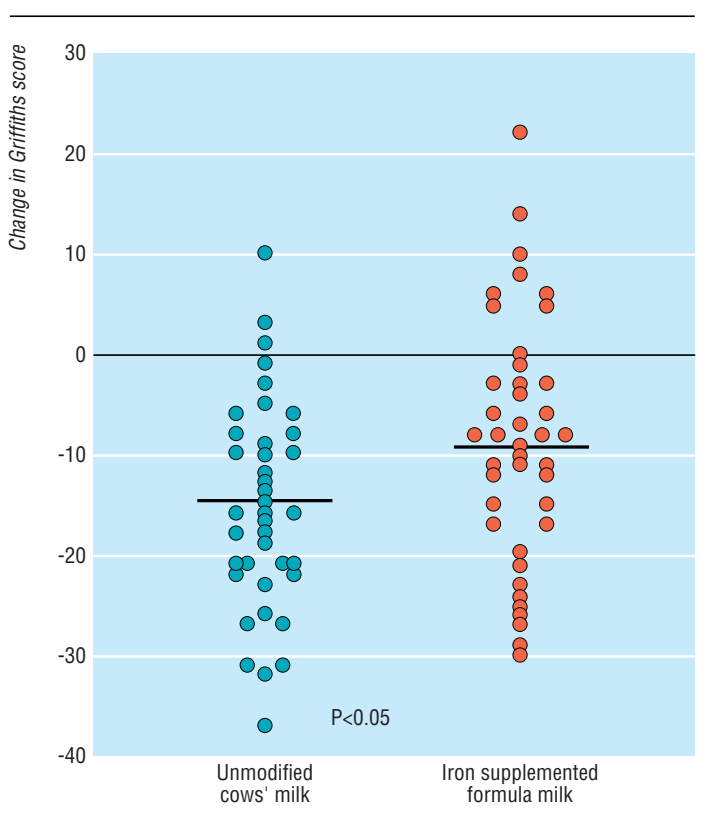

Fig 2 Changes in Griffiths general quotient score between enrolment and 24 months of age in infants receiving unmodified cows' milk or iron supplemented formula milk manuscript, some of the data are incorrect. Figure 1 should have shown that 42 [not 41] infants who received iron supplemented formula milk remained in the study. Figures 2 and 3 should have shown that, due to missing data, comparative studies were carried out on 38 pairs of observations [not individual] in infants receiving unmodified cows' milk; correct versions of figures 2 and 3 appear below. In the results section of the abstract the 95\% confidence intervals for personal and social scores should have read 1.2 to 16.8 [not -5.4 to 17.2]. The conclusions remain unchanged.

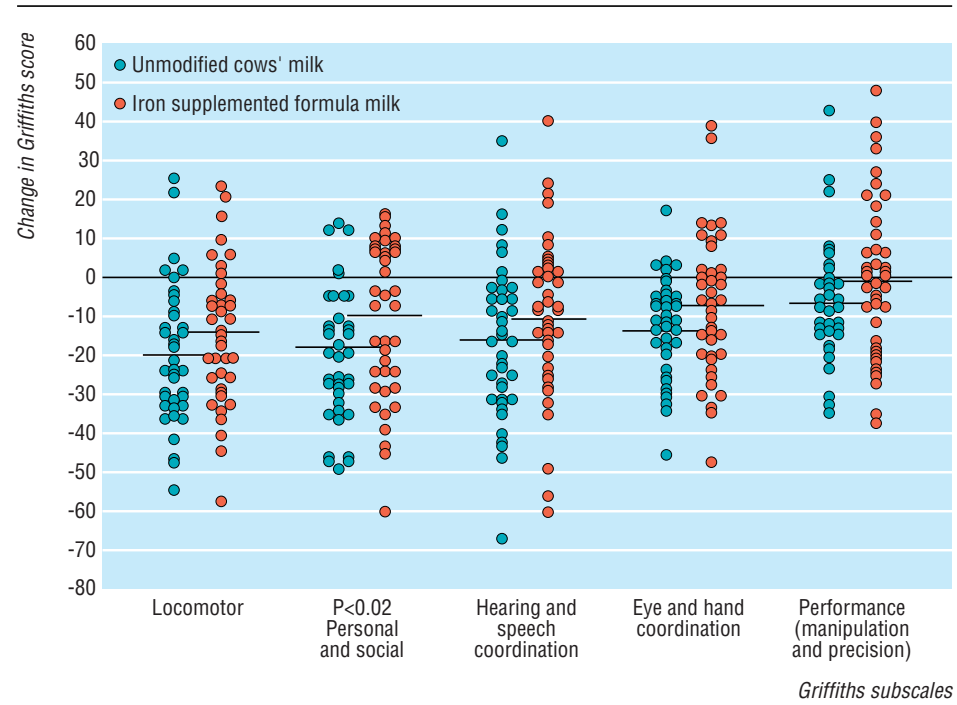

Fig 3 Changes in Griffiths subscales between enrolment and 24 months of age 